\title{
A Full-Scale Study of Flax Fiber-Based Thermal Insulating Slabs on the Attic Floor
}

Authors:

Sergey Romanovskiy, Aleksandr Bakatovich

Publisher: Springer International Publishing

Published in: Sustainability and Automation in Smart Constructions

\section{Abstract}

The main subject of the study is the physical parameters of thermal insulating materials based on flax fiber, including thermal transfer resistance and humidity, determined under operating conditions. In the experiments, slabs based on flax fibers and flax noils were used, as well as thermal insulation material from a mixture of flax and polyester fibers. Fibrous insulation slabs were laid in the attic floor of a one-story residential building located in the countryside in northern Belarus. Monitoring of the parameters studied was carried out in the autumn, winter, and spring. The thermal transfer resistance of the insulated attic floor was determined using heat flow sensors. According to the readings of thermocouples installed inside the structure, temperature distribution graphs were constructed to determine the effectiveness of thermal insulation on the attic floor. At a temperature of $-17^{\circ} \mathrm{C}$, the thermal transfer resistance of insulation was $5.17-5.88\left(\mathrm{~m}^{2 \circ} \mathrm{C}\right) / \mathrm{W}$. The moisture content of thermal insulation materials 
after the winter period was in the range of 5.7-12.3\%. The results obtained prove the effectiveness of thermal insulation slabs based on flax noils.

https://www.springerprofessional.de/en/a-full-scale-study-of-flax-fiber-basedthermal-insulating-slabs-/18377860 